\title{
然
}

Rodrigo Echenique Sanjurjo*

José María Fernández Rodríguez*

\section{EL MERCADO DE DEUDA PRIVADA}

El mercado de préstamos apalancados crece dinámicamente alimentado por la desintermediación bancaria, la financiación de operaciones de private equity y la demanda de inversores en busca de retorno y diversificación. Un análisis histórico de los distintos activos y estrategias de inversión en este mercado evidencia su favorable comportamiento en términos absolutos y relativos frente a otros activos. La creciente preocupación por el deterioro en las prácticas, precios y condiciones aplicadas a algunos segmentos de este mercado debe ser ponderada teniendo en cuenta las características diferenciales de sus estrategias y activos de inversión y la experiencia y dispersión de resultados demostrada históricamente por sus gestores.

Palabras clave: financiación apalancada, deuda privada, préstamos directos, préstamos sindicados, mezzanine, distress.

Clasificación JEL: E44, F34.

\section{Financiación apalancada y deuda privada}

Esta última década ha sido testigo de un importante crecimiento de la deuda a nivel mundial, pasando su saldo vivo de 116 billones de dólares en 2007 a más de 164 billones de dólares al cierre de $2016{ }^{1}$. De entre los diferentes segmentos que componen el mercado de deuda, uno de los que está experimentando mayor crecimiento y suscitando mayor interés entre inversores y supervisores es el denominado

\footnotetext{
* Socios de Altamar Credit.

Versión de mayo de 2019.

DOI: https:/doi.org/10.32796/bice.2019.3111.6820

1 Según cifras del Fondo Monetario Internacional.
}

mercado de financiación apalancada (leveraged finance en su traducción al inglés).

El término financiación apalancada hace referencia al uso de instrumentos de deuda, en formato bono o préstamo, para financiar la adquisición, expansión, recapitalización o actividad de una empresa por un importe de deuda tal que la ratio de deuda neta dividida por el beneficio antes de intereses, amortizaciones, depreciaciones e impuestos (ebitda en su acrónimo inglés) sea superior a cuatro.

Dentro de este mercado hay tres segmentos diferenciables:

- El mercado de bonos de alto rendimiento (high yield en inglés), también conocido como mercado de bonos especulativos o basura. Se trata de bonos con $D$ 
cupón fijo, duración cercana a los 4 años, vencimiento de entre 7 y 10 años, no colateralizados (unsecured) y que suelen incorporar cláusulas que protejan frente a una refinanciación en los dos o tres primeros años de vida del bono (call protection). Estos bonos financian a empresas con rating crediticio por debajo del grado de inversión y de ebitda cercano a o superior a los 100 millones de euros, teniendo por ello importes de emisión de entre 300 y varios miles de millones de euros, por lo que tienen liquidez en un mercado secundario organizado.

- El mercado de préstamos sindicados bancarios (leveraged loans en inglés), también conocido como mercado de senior loans. Se trata de préstamos a tipo variable, con duración cercana al medio año, con vencimiento contractual entre 5 y 7 años, con rating inferior a grado de inversión o sin rating, que financian a empresas con ebitda superior a los 75 millones de euros, que son senior en la estructura de capital y que están colateralizados (secured) con garantías de primer rango (first lien). Suelen tener saldos superiores a los 300 millones de euros y tienen cierta liquidez en un mercado secundario no organizado u OTC (over the counter) por lo que disfrutan de una referencia de precio de mercado diario.

- El mercado de deuda privada (private debt en inglés). Se trata de préstamos a tipo variable, con duración cercana al medio año, con vencimiento contractual entre 5 y 7 años, que financian a empresas con ebitda positivo de hasta 75 millones de euros, sin rating y que pueden ser senior en la estructura de capital o junior y estar colateralizados o en algunas circunstancias no estarlo (caso de la deuda mezzanine estadounidense). Debido a su importe nominal reducido (menor a 250 millones de euros), no disponen de liquidez ni precio observable.

Tanto los préstamos sindicados como los privados pueden englobarse dentro del concepto de préstamos apalancados, si bien el mercado financiero hace una clara distinción entre ellos, pues son mercados con atributos y comportamiento diferenciado.

El mercado de bonos de alto rendimiento se desarrolló en los años ochenta y noventa en Estados Unidos (EE UU) y más recientemente en Europa. El mercado de préstamos sindicados bancarios y el de deuda privada también tuvieron su origen en EE UU y su crecimiento ha disfrutado de una notable aceleración en los últimos diez años, como refleja el Gráfico 1.

Los mercados de préstamos apalancados han crecido sustancialmente en la última década. El mercado de préstamos sindicados, medido en términos de su saldo vivo, era, al cierre de 2018, 2,3 veces más grande que en 2007, alcanzando 1,2 billones de dólares, una dimensión similar al mercado de bonos de alto rendimiento ${ }^{2}$. Por su parte, el mercado de deuda privada es más difícil de cuantificar y suele aproximarse por el importe de activos bajo gestión de los fondos que invierten en este mercado, lo que fijaba su dimensión en $638 \mathrm{mi}-$ les de millones de euros a finales de 2018, es decir, 3,1 veces más grande de lo que era a finales de 2007.

\footnotetext{
2 Tanto los préstamos sindicados como los bonos de alto rendimiento sirven a un universo similar de empresas, si bien se trata de dos instrumentos financieros muy distintos, pues mientras que los préstamos son a tipo flotante, tienen baja duración y pueden ser secured, los bonos suelen ser a tipo fijo, tienen más elevada duración, y por ello mayor riesgo ante subidas de tipos, y suelen ser unsecured, o dicho de otra forma, no tener garantías, siendo más junior en la estructura de capital de una empresa.
} 


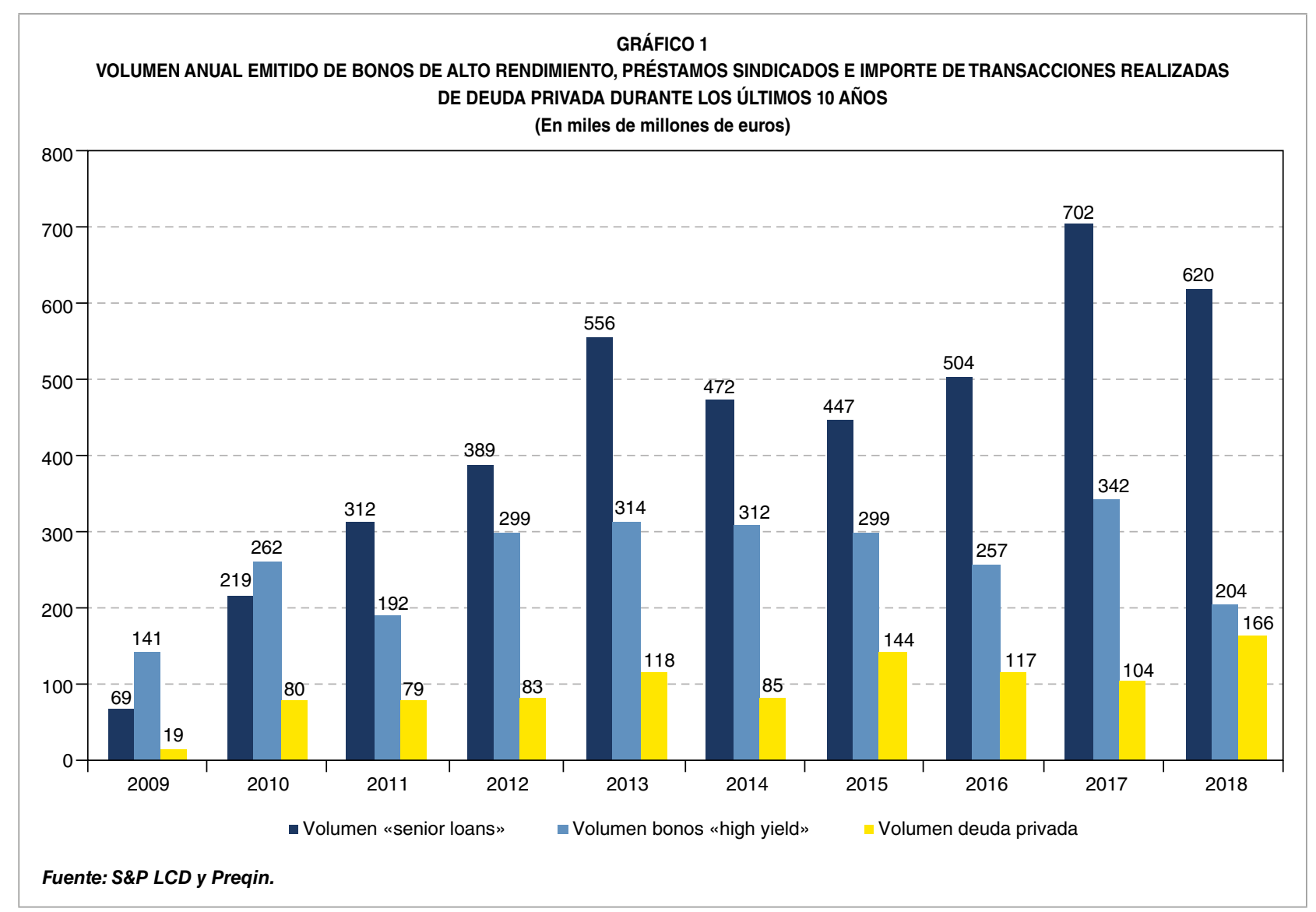

Tan importante crecimiento resulta, desde el punto de vista de la oferta, de la progresiva retirada de los bancos de este mercado. Históricamente los bancos financiaban estos préstamos, pero desde hace ya más de dos décadas en EE UU, y de forma reciente en Europa, la participación de bancos en este mercado viene reduciéndose, limitándose a su intermediación en la estructuración de grandes operaciones y siendo estos cada vez menos relevantes como inversores a plazo. Las razones de esta tendencia hay que buscarlas en la regulación bancaria postcrisis financiera (Dodd Frank, Leveraged Lending Guidelines y Basilea III, principalmente), que entre otras cosas hace más oneroso en términos de consumo de capital el otorgamiento y el mantenimiento en balance de estos préstamos. Fruto de todo esto, el peso de entidades bancarias en este mercado ha caído hasta un entorno del 7\% en EE UU y del 23\% en Europa ${ }^{3}$.

Desde el punto de vista de la demanda, los bajos tipos de interés imperantes en los mercados monetarios y de capitales de estos pasados años han tenido, como efecto secundario, que un número creciente de inversores sean demandantes de estos préstamos, cuyo perfil riesgo retorno los hace muy atractivos como parte de una cartera de inversión, como se muestra más adelante. La pujanza de la demanda está facilitando un rápido desarrollo del mercado, pero también contribuyendo a un deterioro de las condiciones financieras de los préstamos y a una moderación del retorno por unidad de riesgo, lo que hará más proclive a este mercado a $D$

\footnotetext{
3 Fuente: S\&P LCD
} 
Rodrigo Echenique Sanjurjo y José María Fernández Rodríguez

sufrir un importante ajuste cuando llegue la próxima crisis financiera.

\section{Ventajas e inconvenientes de los préstamos apalancados como activo de inversión}

Entre las ventajas de los préstamos privados a empresas como activo de inversión podrían destacarse su retorno financiero y su moderada volatilidad, su baja o negativa correlación histórica con otros activos financieros de renta fija y su buen comportamiento en fases alcistas de tipos de interés. Por todas estas características, este es un activo financiero atractivo como componente de una cartera de inversión diversificada. Ello no obstante, hay también que tener en consideración que se trata de un activo con ciertas debilidades, algunas de tipo coyuntural y otras derivadas de sus características estructurales.

A continuación se presentan algunas de sus principales características: en primer lugar, las que podrían ser consideradas como sus atributos más favorables, diferenciando en cuanto proceda entre préstamos sindicados y préstamos directos.

\subsection{Retorno y volatilidad}

Los mercados de préstamos sindicados y préstamos directos tienen un perfil de rentabilidad y comportamiento financiero diferente. Ello refleja, en parte, la iliquidez del mercado de préstamos directos. Fruto de esta iliquidez, los préstamos directos pagan un interés superior $y$, al no haber una referencia de mercado para los mismos, su valoración tiende a ser estimada de forma más teórica y reflejando de forma subjetiva la expectativa de repago. Ello no obstante, todos los fondos que invierten en este mercado son auditados anualmente.

El retorno de estos préstamos tiene dos componentes:

- La rentabilidad que devengan y pagan los préstamos. El retorno de un préstamo tiene tres partes: el tipo base (euribor o libor), el diferencial o spread sobre el tipo base y la comisión de estructuración de la operación. Es frecuente, además, que el tipo base esté limitado con un suelo en $0 \%$ o superior.

- La valoración de mercado del préstamo, cuando esta existe, que refleja el valor teórico de sus flujos de caja descontados y el equilibrio entre oferta y demanda del mismo. Desde el punto de vista de análisis crediticio, esta valoración tenderá a estar cerca de la par (por ofrecer un tipo de interés variable), a no ser que la expectativa de recobro del préstamo empeore o se produzca un impago, en cuyo caso el valor estimado del préstamo caerá. Adicionalmente, en el caso de los préstamos sindicados, al cotizar en un mercado secundario al mostrador u over the counter, los movimientos técnicos de oferta y demanda, la liquidez de mercado, la coyuntura macroeconómica y los riesgos geopolíticos tienen una influencia directa en la valoración de mercado de los préstamos y, por tanto, están sujetos a cierta volatilidad no vinculada exclusivamente a su calidad crediticia.

Habitualmente, el seguimiento del comportamiento de este mercado se hace a través de índices, tal como se presenta a continuación. 
Mercado de préstamos sindicados

Los préstamos sindicados tienen unos saldos vivos de cientos o miles de millones de euros. Por ello disfrutan de liquidez, y gracias a ello ha sido posible construir índices que sigan la evolución de sus precios. De entre estos índices destacan los publicados por Credit Suisse y los de Standard \& Poor's (S\&P).

La Tabla 1 presenta los retornos anuales a 1, 3, 5 y 10 años ofrecidos por el índice europeo 4 y estadounidense de Credit Suisse en comparación con los retornos generados por el Bund alemán (estimado a través del índice de S\&P), por el mercado de bonos de alto rendimiento (estimado a través del índice de Bloomberg Barclays de bonos high yield) y por el índice de bonos corporativos de Barclays. De esta comparativa cabe concluir el atractivo financiero de este activo en términos absolutos y relativos en comparación con otros activos de renta fija y en especial si se toma en consideración el retorno ajustado por riesgo.

\footnotetext{
4 Credit Suisse Western European Leveraged Loan Index y Credit Suisse Leveraged Loan Index. Este último es tomado como referencia del mercado estadounidense.
}

\section{Mercado de préstamos directos}

El análisis del perfil temporal de retornos del mercado de préstamos directos es más difícil de realizar por su carácter ilíquido. Ello no obstante, hay dos índices que siguen el comportamiento de este mercado en EE UU, el compilado por Cliffwater y el de Burgiss, siendo el primero un índice compuesto por una cartera de préstamos y el segundo, un índice compuesto por una cartera de fondos que conceden estos préstamos, por lo que usaremos el primero en este apartado.

El Cliffwater direct lending index mide el retorno de una cartera de más de seis mil préstamos directos a empresas medianas norteamericanas que en su conjunto alcanzan un importe de 97 mil millones de dólares.

El retorno anualizado en dólares de este índice, desde el año 2004, es del 9,7\%. El retorno de este índice se compara en la Tabla 2 con el de los mercados de préstamos sindicados y de bonos de alto rendimiento estadounidenses, lo que pone de manifiesto que, en 10 de los últimos 13 años, el mercado de préstamos directos ha batido en retorno a los otros dos mercados.

TABLA 1

RETORNO, RIESGO Y REMUNERACIÓN DEL RIESGO DE VARIOS ACTIVOS DE RENTA FIJA A DICIEMBRE DE 2018

\begin{tabular}{|c|c|c|c|c|c|c|c|c|c|c|c|c|}
\hline \multirow[b]{2}{*}{ A diciembre de 2018} & \multicolumn{4}{|c|}{ Retornos } & \multicolumn{4}{|c|}{ Riesgo (volatilidad mensual) } & \multicolumn{4}{|c|}{ Relación retorno-riesgo } \\
\hline & $\begin{array}{c}1 \\
\text { año }\end{array}$ & $\begin{array}{c}3 \\
\text { años }\end{array}$ & $\begin{array}{c}5 \\
\text { años }\end{array}$ & $\begin{array}{c}10 \\
\text { años }\end{array}$ & $\begin{array}{c}1 \\
\text { año }\end{array}$ & $\begin{array}{c}3 \\
\text { años }\end{array}$ & $\begin{array}{c}5 \\
\text { años }\end{array}$ & $\begin{array}{c}10 \\
\text { años }\end{array}$ & $\begin{array}{c}1 \\
\text { año }\end{array}$ & $\begin{array}{l}3 \\
\text { años }\end{array}$ & $\begin{array}{c}5 \\
\text { años }\end{array}$ & $\begin{array}{c}10 \\
\text { años }\end{array}$ \\
\hline S\&P Euro-Bund & $3,3 \%$ & $3,2 \%$ & $5,2 \%$ & $5,2 \%$ & $4,01 \%$ & $4,54 \%$ & $4,52 \%$ & $5,36 \%$ & 0,82 & 0,71 & 1,14 & 0,97 \\
\hline $\begin{array}{l}\text { BBG Barclays Global High } \\
\text { Yield }\end{array}$ & $-5,5 \%$ & $4,6 \%$ & $2,9 \%$ & $10,6 \%$ & $3,45 \%$ & $4,49 \%$ & $4,77 \%$ & $7,65 \%$ & $-1,60$ & 1,01 & 0,61 & 1,39 \\
\hline $\begin{array}{l}\text { Bloomberg Barclays } \\
\text { Global Aggregate }\end{array}$ & & & & & & & & & & & & \\
\hline Corporate Total Return & $-3,8 \%$ & $1,4 \%$ & $2,2 \%$ & $4,9 \%$ & $2,18 \%$ & $3,01 \%$ & $3,10 \%$ & $3,82 \%$ & $-1,73$ & 0,47 & 0,71 & 1,29 \\
\hline CS WELLI & $0,5 \%$ & $3,4 \%$ & $3,1 \%$ & $8,3 \%$ & $2,03 \%$ & $2,21 \%$ & $1,93 \%$ & $5,01 \%$ & 0,27 & 1,55 & 1,59 & 1,66 \\
\hline CS LLI & $1,1 \%$ & $5,0 \%$ & $3,3 \%$ & $8,3 \%$ & $3,08 \%$ & $2,79 \%$ & $2,60 \%$ & $4,89 \%$ & 0,37 & 1,80 & 1,28 & 1,70 \\
\hline
\end{tabular}


TABLA 2

RETORNO ANUAL DEL MERCADO DE PRÉSTAMOS DIRECTOS COMPARADO CON OTROS ACTIVOS DE RENTA FIJA

\begin{tabular}{|c|c|c|c|}
\hline Año & CDLI & $\begin{array}{c}\text { Bloomberg } \\
\text { Barclays HY } \\
\text { Index }\end{array}$ & $\begin{array}{c}\text { S\&P / LSTA } \\
\text { LLI }\end{array}$ \\
\hline 2005 & $10,10 \%$ & $2,74 \%$ & $5,06 \%$ \\
2006 & $13,70 \%$ & $11,87 \%$ & $6,74 \%$ \\
2007 & $10,23 \%$ & $1,88 \%$ & $2,08 \%$ \\
2008 & $-6,50 \%$ & $-26,15 \%$ & $-29,10 \%$ \\
2009 & $13,18 \%$ & $58,21 \%$ & $51,62 \%$ \\
2010 & $15,79 \%$ & $15,11 \%$ & $10,13 \%$ \\
2011 & $9,75 \%$ & $4,98 \%$ & $1,51 \%$ \\
2012 & $14,03 \%$ & $15,81 \%$ & $9,67 \%$ \\
2013 & $12,68 \%$ & $7,46 \%$ & $5,29 \%$ \\
2014 & $9,57 \%$ & $2,46 \%$ & $1,59 \%$ \\
2015 & $5,54 \%$ & $-4,46 \%$ & $-0,70 \%$ \\
2016 & $11,24 \%$ & $17,14 \%$ & $10,11 \%$ \\
2017 & $8,62 \%$ & $7,5 \%$ & $4,14 \%$ \\
\hline Fuente: Cliffwater, Bloomberg, S\&P. & \\
\hline
\end{tabular}

\subsection{Correlación con otros activos financieros}

Otra de las características del mercado de préstamos apalancados es su correlación con otros activos financieros. En efecto, y tal como evidencia la Tabla 3, las correlaciones con otros activos son bajas o incluso negativas. Esta cualidad hace de este un activo particularmente atractivo como integrante de una cartera de inversión. La raíz de este comportamiento hay que buscarla en el perfil de riesgo y retorno de estos activos, pero también en el hecho de que, por tratarse de préstamos a tipo de interés flotante, están sujetos a menor volatilidad en precio ante cambios en los tipos de interés, siempre y cuando la posibilidad de recobro se mantenga estable.

\subsection{Riesgo de impago y expectativa de recobro}

Como continuación al punto anterior, otra de las variables definitorias de este activo es su riesgo de crédito. El mercado de préstamos sindicados o el de préstamos directos se caracterizan porque las empresas deudoras no tienen rating o este suele ser inferior al grado de inversión. En el primero de los casos, ello puede responder tanto al riesgo de la empresa como a que, por su dimensión, no incurra en el coste de obtener y mantener un rating.

Las empresas deudoras de un préstamo sindicado tienen un rating por debajo del grado de inversión como consecuencia, generalmente, de sus altos niveles de apalancamiento, su calidad crediticia estimada, cambios sustanciales en el gobierno corporativo y estrategia de negocio o su tamaño relativo reducido. Por su parte, el mercado de préstamos directos se compone de compañías sin rating crediticio como consecuencia de ser un mercado que, por el tamaño de sus compañías y préstamos, no $\square$

TABLA 3

ANÁLISIS DE CORRELACIÓN DE VARIOS ACTIVOS DE RENTA FIJA (PERIODO 1999-2015)

\begin{tabular}{|c|c|c|c|c|c|}
\hline & $\begin{array}{l}\text { Bonos grado } \\
\text { de inversión }\end{array}$ & $\begin{array}{l}\text { Préstamos } \\
\text { sindicados }\end{array}$ & $\begin{array}{c}\text { Préstamos empresas } \\
\text { medianas }\end{array}$ & $\begin{array}{c}\text { Bonos Gobierno } \\
\text { EE UU }\end{array}$ & S\&P 500 \\
\hline Bonos grado de inversión & 1,00 & 0,38 & 0,30 & 0,37 & 0,12 \\
\hline Préstamos sindicados & & 1,00 & 0,91 & $-0,54$ & 0,55 \\
\hline Préstamos empresas medianas & & & 1,00 & $-0,48$ & 0,52 \\
\hline Bonos Gobierno EE UU & & & & 1,00 & $-0,64$ \\
\hline S\&P 500 & & & & & 1,00 \\
\hline
\end{tabular}

Fuente: TIAA GAM «Private debt: The opportunity for income and diversification with illiquid assets». 
cuenta con un mercado secundario y, por tanto, no está institucionalizado como el de préstamos sindicados. Las transacciones se realizan de forma bilateral o en formato club dea/ ${ }^{5} \mathrm{y}$ consecuentemente los inversores no necesitan ratings externos de los préstamos.

Fruto de lo anterior, el riesgo de crédito de ambos mercados es percibido como elevado, y ello es uno de los factores que tradicionalmente ha desincentivado a algunos inversores a la hora de invertir. A este respecto es importante caracterizar adecuadamente los dos factores importantes que definen el riesgo de crédito.

\section{La probabilidad o tasa de impago (default rate)}

Según Moody's, la tasa de impago media de la deuda con grado de inversión durante el periodo entre 1920 y 2017 fue del 0,15\% anual, mientras que en el caso de la deuda por debajo del grado de inversión esta cifra fue del 2,8\%. Precisando más, si nos centramos en el mercado de préstamos sindicados, el Gráfico 2 refleja que durante los últimos once años, con la excepción de marcados episodios de crisis financiera, las tasas de impago se han mantenido en cifras muy moderadas, siendo en promedio del $2,2 \%$ anual 6 .

\section{La tasa de pérdida realizada (loss given default)}

En caso de impago, la pérdida final para el inversor en una cartera de préstamos depende de la tasa de recuperación de los préstamos una vez han sido refinanciados, reestructurados o liquidados después de haber hecho default. A su vez, la tasa de recuperación depende del grado de prelación (seniority) del préstamo en la estructura de capital y de la existencia o no de garantías ${ }^{7}$ que actúen $\triangleright$

S\&P LCD

7 Los préstamos suelen disponer de garantías secured.

TASAS DE IMPAGOS DE PRÉSTAMOS SINDICADOS EN LOS MERCADOS EUROPEOY ESTADOUNIDENSE

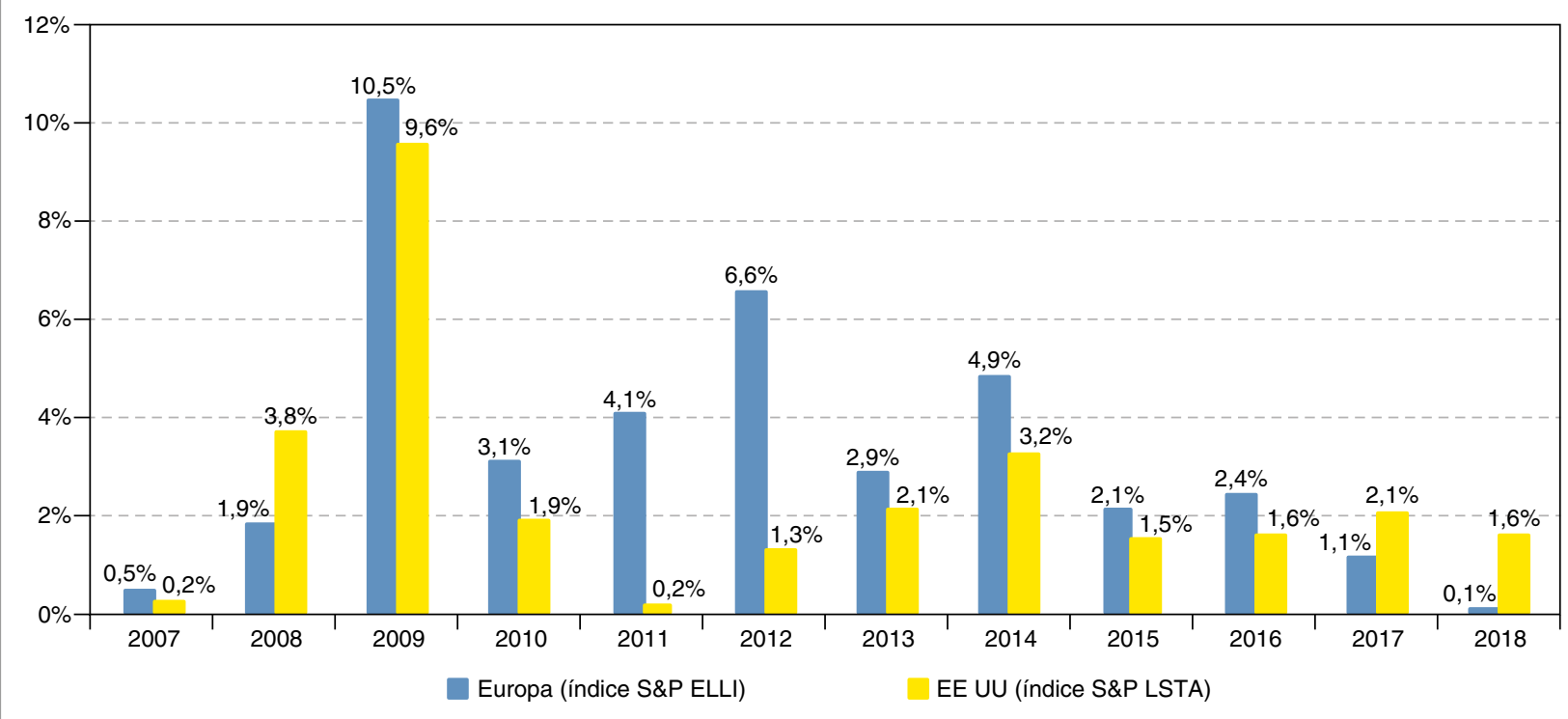

Fuente: S\&P LCD. 
como colateral en caso de impago. Estas garantías pueden haber sido asignadas específicamente al préstamo en cuestión o resultar de la existencia de otra deuda más subordinada o del colchón que representa el capital de la empresa, siempre último en el orden de prelación sobre los activos del balance de una empresa. El Gráfico 3 presenta las tasas medias de recuperación por tipo de deuda en caso de impago ${ }^{8}$.

Los préstamos first-lien o de primer rango, y en mayor medida en el caso de los préstamos a empresas medianas, han disfrutado tradicionalmente de altas tasas de recuperación. Ello ha permitido que, aun en circunstancias en las que haya podido haber impagos, la pérdida final fuera pequeña para el acreedor.

Recientemente Moody's llamó la atención al mercado acerca de la disminución en la tasa de recuperación esperada en el caso de los préstamos sindicados ${ }^{9}$. Tras esta advertencia

8 S\&P Credit Pro. Datos para el periodo 1983-2018

9 «Convergence of bonds and loans sets stage for worse recoveries in the next downturn", Moody's, agosto de 2018. de la agencia reside el crecimiento exponencial experimentado durante los últimos años en el apetito por este tipo de activo por parte del mercado institucional, lo que ha ocasionado un desequilibrio entre la oferta y la demanda de préstamos y el consiguiente deterioro en los términos y documentación de estos. Ello ha tenido como consecuencia que casi 4 de cada 5 préstamos sindicados no incluyan obligaciones (covenants ${ }^{10}$ ) financieras que fuerzan a realizar un seguimiento regular de ciertos parámetros financieros como apalancamiento, cobertura, capex, etcétera, y cuyo incumplimiento otorga a los prestamistas la capacidad de forzar una reestructuración de los préstamos o a la adopción de otras medidas encaminadas a restaurar el equilibrio financiero o la composición de la estructura de capital de la empresa. Además, los deudores están $\triangleright$

10 Un covenant habitualmente usado es el nivel de apalancamiento medido como la ratio entre la deuda neta y el ebitda de la empresa. La ruptura de covenant por su incumplimiento implica la obligación de remediar la situación mediante, por ejemplo, una inyección de capital en la empresa o una reestructuración del préstamo o su amortización parcial.

GRÁFICO 3

TASAS DE RECUPERACIÓN DE PRÉSTAMOS SINDICADOS Y DIRECTOS A EMPRESAS DE TAMAÑO MEDIO FRENTE A OTROS PRÉSTAMOS Y BONOS

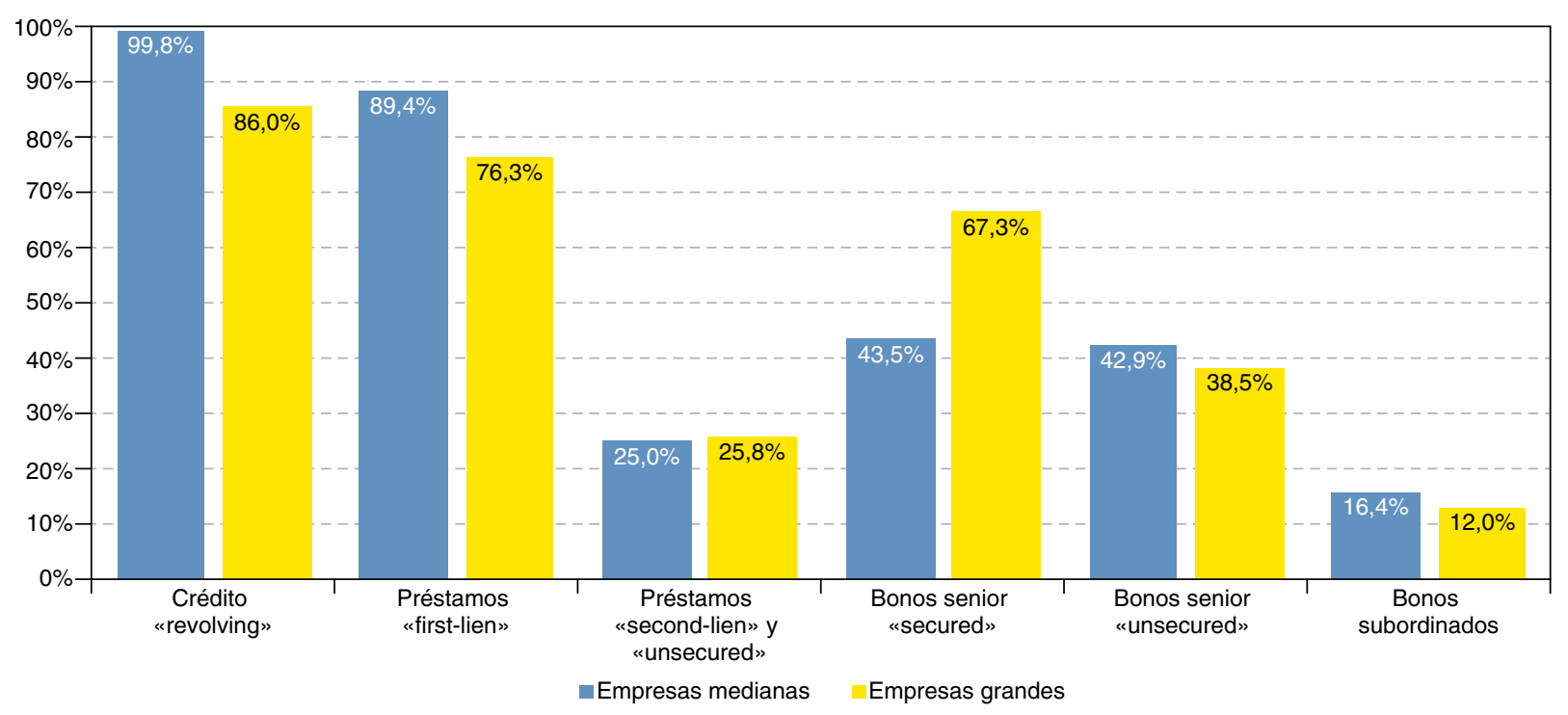

Fuente: S\&P Credit Pro, datos para el periodo 1983-2018. 
aprovechando esta situación para habilitarse, en los contratos de préstamo, poderes relativos a la venta de los activos que sirven de colateral o a la retención y uso de los ingresos generados por la venta de activos de la empresa. Todo ello hace pensar que la próxima ronda de reestructuraciones de préstamos podría hacerse sobre deudores con una situación financiera más deteriorada o menores colaterales para compensar a los acreedores, por lo que Moody's espera que las tasas de recuperación en el mercado de préstamos sean más bajas y más cercanas a las del mercado de bonos de alto rendimiento, que han sido tradicionalmente inferiores.

Es importante resaltar que este deterioro de las condiciones crediticias es atribuible al mercado de préstamos sindicados como consecuencia de que su crecimiento exponencial durante los últimos diez años ha ocasionado desequilibrios entre la oferta y la demanda y del cada vez mayor apetito por este activo por parte del mercado institucional que ha acelerado los tiempos de ejecución haciendo converger ciertas características estructurales de este mercado con el de bonos high yield. Estos aspectos seculares no se dan, sin embargo, en el mercado de préstamos directos, donde los préstamos siguen contando mayoritariamente con sólidos elementos de protección del prestamista (covenants financieros, derechos de veto, control sobre adquisiciones o pago de dividendos, etcétera).

En cualquier caso, el análisis histórico de tasas de impago y recuperación evidencia que el riesgo medio histórico de estos préstamos es inferior al que buena parte de los agentes económicos percibe. Fruto de ello, también, es que conforme este mercado va siendo menos desconocido, aumenta el apetito inversor.

\subsection{Comportamiento en fases alcistas de tipos}

Otra de las características esenciales de este tipo de activos es su baja duración por el carácter flotante de los tipos que definen su rendimiento financiero. Por este motivo, son activos que se comportan bien en fases alcistas de ciclo, a diferencia de lo usual en otros mercados de renta fija. El Gráfico 4 presenta el retorno generado por los índices Credit Suisse Leverage Loan Index y Credit Suisse Western European Loan Index durante varios periodos de los últimos veinte años en que subieron los tipos de los bancos centrales estadounidense y europeo, confirmando que la evolución en precio de sus índices fue positiva durante periodos de alzas de tipos de interés.

\subsection{Liquidez}

Por sus mayores saldos vivos, que pueden llegar a los miles de millones por préstamo, los préstamos sindicados disfrutan de liquidez con operaciones cruzadas diariamente y precios observables a través de plataformas electrónicas para especialistas o, en el caso del mercado estadounidense, a través de alguno de los ETF o instituciones de inversión colectiva (mutual funds) que existen.

En el caso de los préstamos directos, no hay liquidez $y$, por tanto, los inversores suelen operar bajo un esquema de comprar y mantener hasta vencimiento (buy and hold). La forma habitual de hacer líquida la inversión antes de vencimiento es mediante su refinanciación. Si se quiere hacer líquido todo o parte de uno de estos préstamos, ello suele llevar aparejados importantes costes transaccionales. Por otra parte, la contraprestación de esta prima de $\triangle$ 


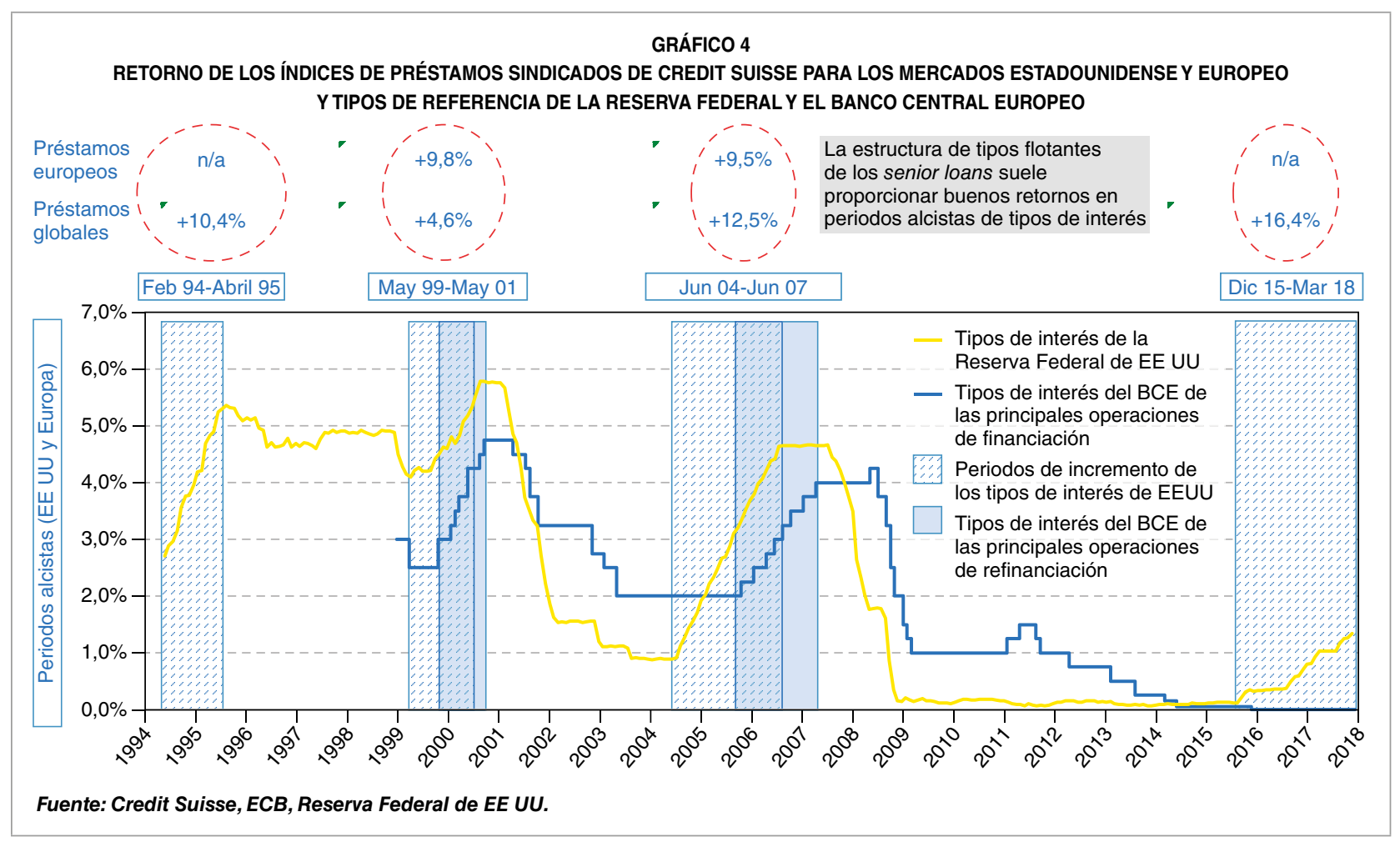

iliquidez es una compensación vía retorno financiero superior, estimado en unos tres puntos porcentuales adicionales.

\subsection{Transparencia}

El carácter privado del mercado de préstamos directos lo convierte en un mercado difícil de monitorizar. Ello, si cabe, es más cierto aún fuera de EE UU, debido al menor historial, profundidad y grado de desarrollo de este mercado en otras geografías. El caso del mercado de préstamos sindicados es más fácilmente analizable, pues hay precios y transacciones regulares en el mismo y en sus diferentes geografías. Además, dado que en EE UU se han desarrollado vehículos de inversión que permiten que los inversores minoristas accedan fácilmente a este mercado, el seguimiento de su comportamiento y caracterización de su riesgo y retorno es más accesible.

\subsection{Complejidad técnica}

Se trata de un mercado sofisticado, cuya jerga puede inducir a confusión ${ }^{11}$ y relativamente nuevo fuera del ámbito de los especialistas en private equity o financiación estructurada. Aun cuando el activo subyacente es relativamente básico, pues se trata de un préstamo a tipo variable, normalmente con reembolso de principal a vencimiento (bullet), su compleja documentación, el tipo y situación de las operaciones que financia y de las estrategias de inversión que ejecuta lo convierten en un mercado técnicamente exigente.

Al tiempo, se trata de un mercado que ha suscitado gran interés y una demanda creciente entre inversores ávidos por mejorar sus retornos pero que no siempre son capaces de $D$

11 A menudo se cofunden los conceptos de senior loans, leveraged loans y deuda privada. Incluso el mismo concepto de deuda privada resulta confuso, pues no incluye toda la deuda que pueda ser considerada privada al circunscribirse usualmente a la deuda corporativa. 
discernir los segmentos diferenciados de este mercado, ni la calidad de los gestores de inversiones en el mismo, lo que es particularmente relevante si se atiende al estudio sobre dispersión de retornos presentado más adelante en este artículo.

\section{El mercado de préstamos sindicados apalancados (leveraged loans)}

Este mercado de financiación ha adquirido reciente notoriedad merced a su gran crecimiento, que lo ha llevado a situarse a la par en saldo vivo con el mercado de bonos high yield y al deterioro de determinados términos contractuales mayoritariamente aplicados en la estructuración de este tipo de operaciones, lo que ha generado preocupación entre inversores y supervisores. Por este motivo vamos a dedicar este apartado a desgranar un poco más en detalle sus características y su situación actual.

\subsection{Su dinámico crecimiento durante la última década}

El mercado de préstamos apalancados sindicados creció hasta alcanzar su máximo nivel de actividad en 2017, cuando un total de 702.000 millones de euros fueron emitidos, lo que supone una emisión 4,5 veces mayor que la registrada en 2008.

Este crecimiento puede explicarse en términos de los distintos usos posibles dados a estos préstamos, de entre los que destaca la financiación de la expansión de compañías, la financiación de adquisiciones corporativas (leveraged buyouts) generalmente llevadas a cabo por fondos de private equity y la refinanciación o reestructuración de préstamos vivos, como operaciones más relevantes, y la financiación de una distribución de dividendos como transacción más excepcional. La evolución de tipos y diferenciales, la desintermediación de la actividad bancaria, el crecimiento de la industria de private equity y la naturaleza senior y a tipo variable de los mismos los ha convertido en una herramienta preferida por los diferentes participantes del mercado frente a otras soluciones financieras, en particular, los bonos de alto rendimiento.

\subsection{El impacto y rol del crecimiento de las titulizaciones de préstamos}

Las titulizaciones de préstamos o collateralized loan obligations (CLO) han sido otro de los factores impulsores del crecimiento de estos préstamos, habiéndose convertido en su principal comprador. Se estima que la dimensión del mercado de CLO ronda los 740.000 millones de USD.

Un CLO adquiere préstamos sindicados que constituyen el activo del vehículo de titulización. Para financiarlos emiten deuda y capital (equity). Su pasivo queda, así, compuesto por notas con diferentes ratings crediticios, desde AAA a BBB o BB (credit tranches), y capital (equity tranche). Los retornos generados por los préstamos que componen el activo del balance de un CLO remuneran su pasivo comenzando por las notas de mayor rating y terminando por los inversores en el capital, que son los últimos en cobrar.

El modesto retorno de la renta fija tradicional ha animado a un número creciente de inversores institucionales a participar en este mercado, que permite invertir en deuda con $\triangleright$ 


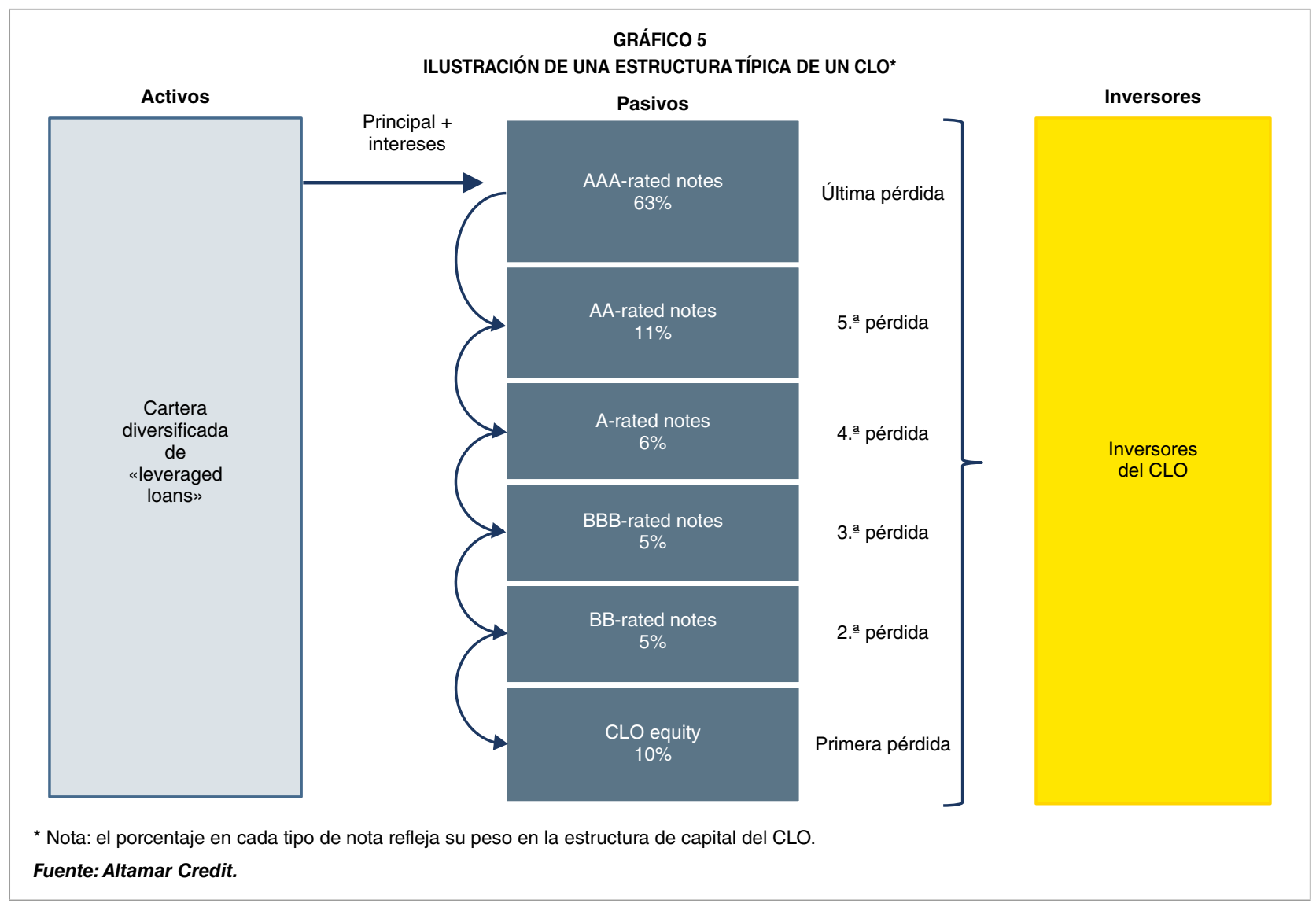

diferentes niveles de rating y retorno y con un perfil de riesgo inferior al percibido si nos atenemos a su comportamiento histórico. En efecto, y en contra de la percepción usual de que los CLO son inversiones de alto riesgo, según datos de S\&P, menos de un $0,5 \%$, del total de 12.500 CLO a los que esta agencia de calificación crediticia otorgó rating, han impagado.

\subsection{El deterioro de las prácticas crediticias del mercado}

Fruto de la pujante demanda y de la competencia en mercado, los deudores han disfrutado de una creciente laxitud en cuanto a la documentación de los contratos de crédito que rigen estos préstamos. Esta se ve reflejada en:
- El paulatino abandono en el uso de obligaciones o covenants financieros que protegen al acreedor a través del establecimiento de una serie de condiciones financieras, normalmente expresadas a través de ratios, que han de ser puntualmente cumplidos por el deudor de manera trimestral o semestral. Así, y según datos de S\&P LCD, mientras que en 2007 era habitual que los préstamos disfrutaran de un promedio de 3,5 covenants, en 2019 el promedio es de 1,3.

- La admisión de interpretaciones de los conceptos financieros cada vez más laxas. Así, por ejemplo, la posibilidad de hacer una interpretación amplia del concepto de ebitda, añadiendo artificialmente a su definición estimaciones sobre sinergias de gastos postadquisición $0 \triangleright$ 
fusión, run rates ${ }^{12}$, costes excepcionales, etcétera, que minoran artificialmente el nivel de apalancamiento de una empresa.

Tradicionalmente era normal disfrutar de covenants financieros que ponían un máximo al grado de apalancamiento medido a través del cociente entre la deuda neta de la empresa y su ebitda o a la cobertura de intereses, medida a través del cociente entre el ebitda de la empresa y la carga de intereses de la deuda o que limitaban la inversión en inmovilizado de la empresa. La ruptura de estos covenants lleva aparejada la necesidad de reestructurar el préstamo (con algún mecanismo de compensación al acreedor) o de aportar capital para restablecer el equilibrio financiero.

Además de estas ratios, tradicionalmente se establecían restricciones en cuanto al uso a

12 Run rate se refiere a extrapolaciones optmistas de los resultados de una empresa al futuro. dar a los fondos o a los activos de la compañía o a su capacidad para distribuir dividendos en tanto no se redujera el apalancamiento. Todas estas condiciones han ido paulatinamente abandonándose, de forma que, en la actualidad, más del $70 \%$ de todos los préstamos de este mercado no disfrutan de estas cláusulas protectoras del acreedor. Ello, en sí mismo, no implica necesariamente que se aumente el riesgo de crédito, pero lo que sí hace más probable es que cuando las compañías incumplen sus obligaciones financieras, o hacen default, sus consecuencias serán más gravosas sobre los acreedores que podrán recuperar, previsiblemente, una menor cantidad del dinero prestado.

El motivo de esta paulatina pérdida aparente de solidez en la estructuración de préstamos apalancados es la evolución lógica y natural de un mercado que se ha institucionalizado crecientemente y que, por tanto, tiende a mimetizarse con mercados más consolidados, $\triangleright$

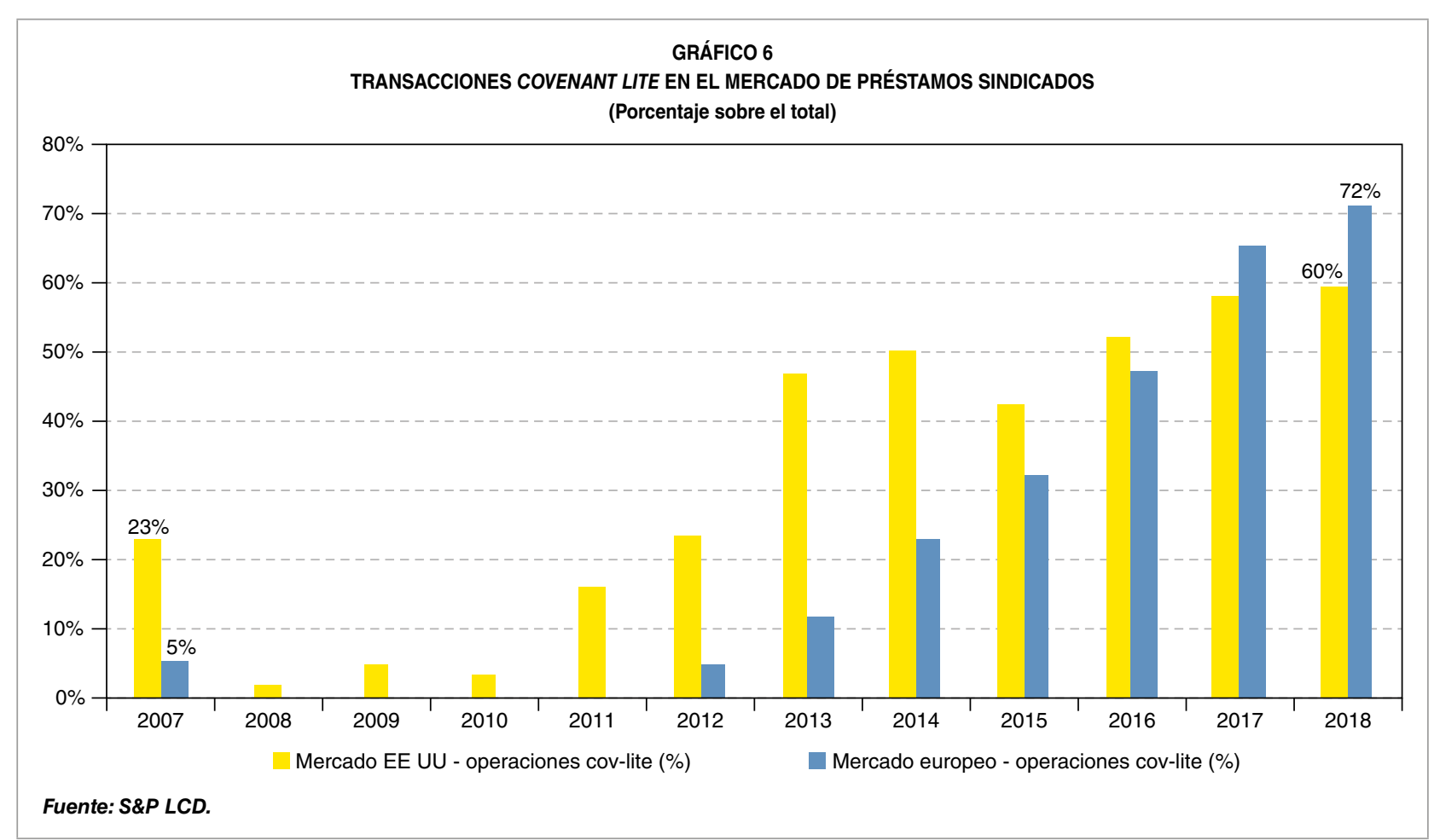


Rodrigo Echenique Sanjurjo y José María Fernández Rodríguez

como el de bonos high yield, donde los elementos de protección al acreedor son significativamente menores que en la financiación bancaria tradicional (que es de donde parte históricamente el mercado de préstamos sindicados).

\subsection{El crecimiento del apalancamiento de las empresas}

Los niveles de apalancamiento financiero de las empresas financiadas por préstamos sindicados se han venido incrementando hasta el punto de que, según datos de S\&P LCD, la ratio promedio de mercado ha alcanzado 5,5 veces ebitda tanto en el mercado estadounidense como en el europeo, lo que la sitúa en niveles similares a los alcanzados en 2007, cuando los mercados europeo y estadounidense registraron 5,9 y 4,9 veces ebitda, respectivamente.

\subsection{El crecimiento de la contribución de capital a las empresas endeudadas}

La cara de la moneda del gradual crecimiento del nivel de apalancamiento reside en la contribución de capital de las operaciones de compra de empresas. La cantidad de capital aportada por el adquirente, usualmente un fondo de private equity, alcanza niveles significativamente superiores a los de la crisis financiera. En efecto, mientras que en Europa y Estados Unidos estas ratios medias de mercado se situaban en el $33 \%$ y $31 \%$ respectivamente en 2007, a septiembre de 2018 estaban en el $47 \%$ y $40 \%$. Esto quiere decir que en caso de que la empresa tenga dificultades para atender su deuda, el colchón de seguridad que representa el capital es notablemente superior a lo que era hace una década, dando por ello mayor nivel de protección al acreedor.

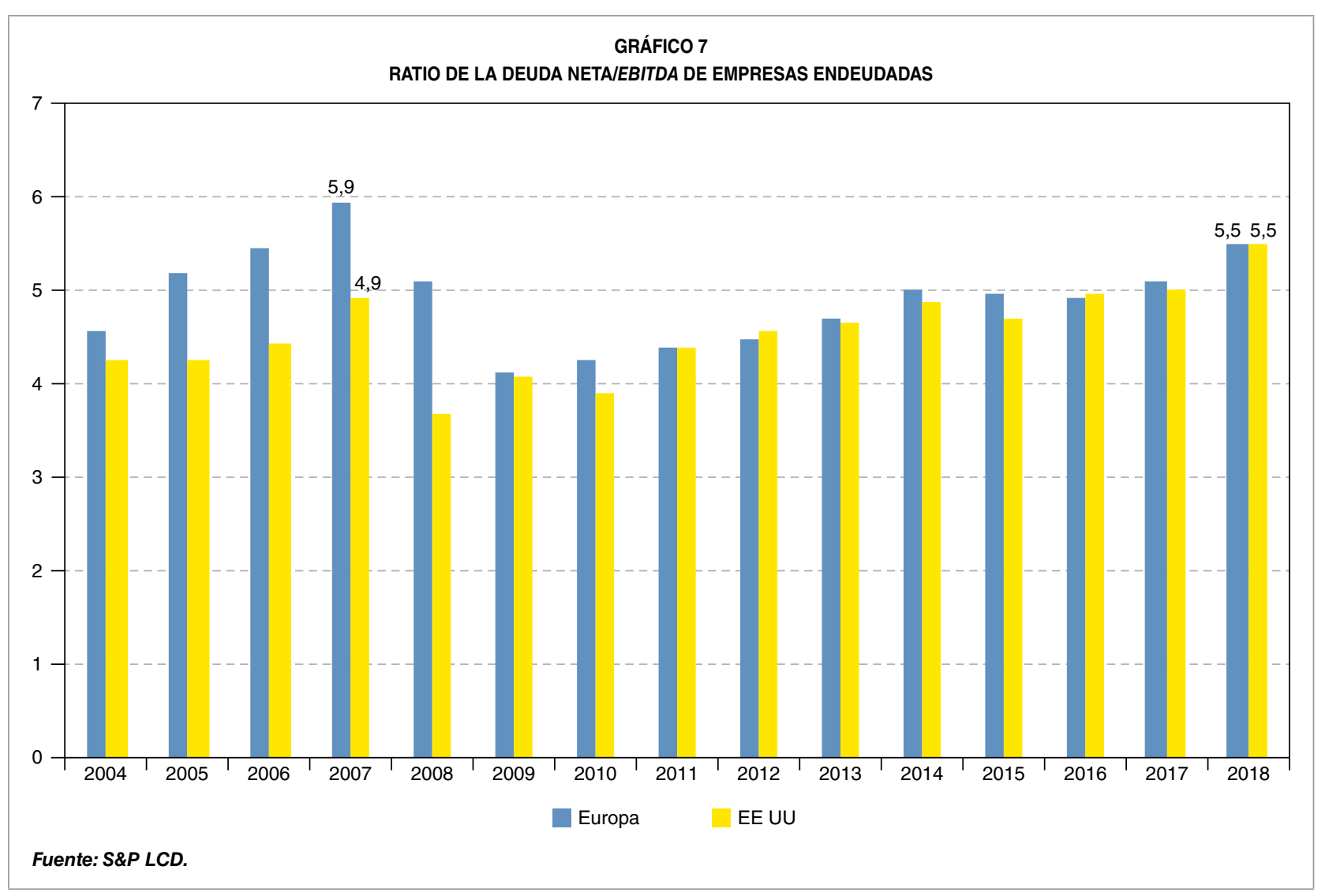




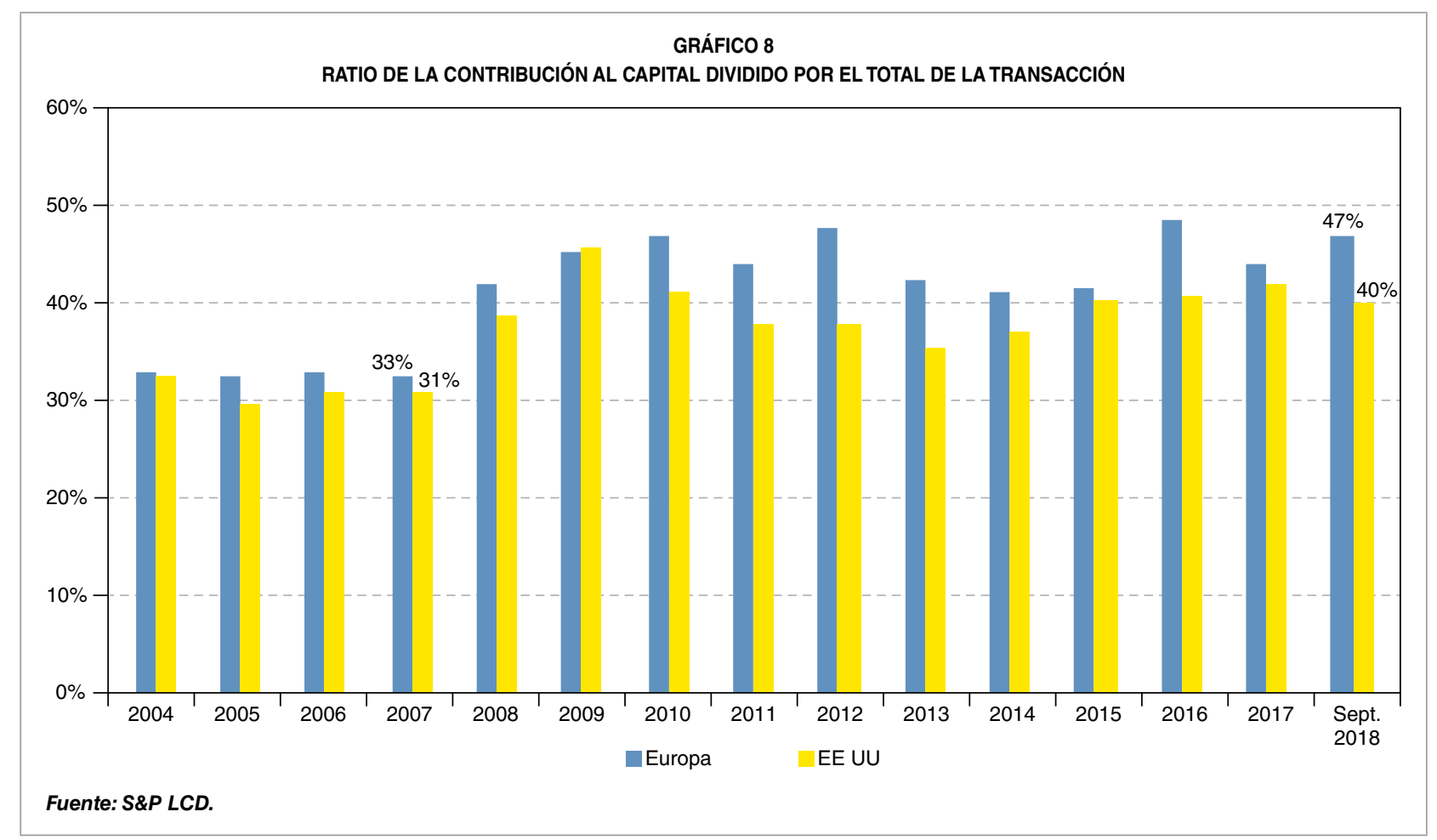

\subsection{Tasas de impago de mercado}

Las tasas de impago se mantienen en niveles históricamente bajos, lo que se explica por el favorable entorno económico y los tipos de interés aplicados a estos préstamos, en especial en la zona euro actualmente, lo que hace más soportable la carga financiera de la deuda.

\subsection{Comportamiento discrepante de los mercados estadounidense $y$ europeo en términos de retornos}

La divergente evolución de los tipos de interés de los bancos centrales a ambos lados del atlántico y de los diferenciales sobre los mismos cotizados por el mercado de préstamos sindicados hace que el retorno nominal de la inversión en préstamos sea superior en EE UU a día de hoy. Si se divide el retorno por el grado de apalancamiento, se obtiene una medición de la remuneración por unidad de riesgo, lo que confirma la ventaja relativa de la inversión en el mercado estadounidense en la actualidad frente al mercado europeo, dado el similar grado de apalancamiento medio actual de ambos mercados.

El aparente interés relativo del mercado americano debe ser, no obstante, ponderado por el riesgo que supone para un inversor europeo invertir en dólares si no cubre el riesgo cambiario. En caso de cubrirlo, habrá de considerar que el coste de dicha cobertura, aproximado por el diferencial de tipos de interés a corto plazo de ambas zonas monetarias, se encuentra también en máximos desde la entrada en vigor del euro.

En conclusión, el mercado de préstamos sindicados ha sido un mercado históricamente muy atractivo como activo de inversión y diversificación. La desintermediación bancaria y el apetito institucional por esta clase de activos han acelerado su crecimiento y han $\triangleright$ 


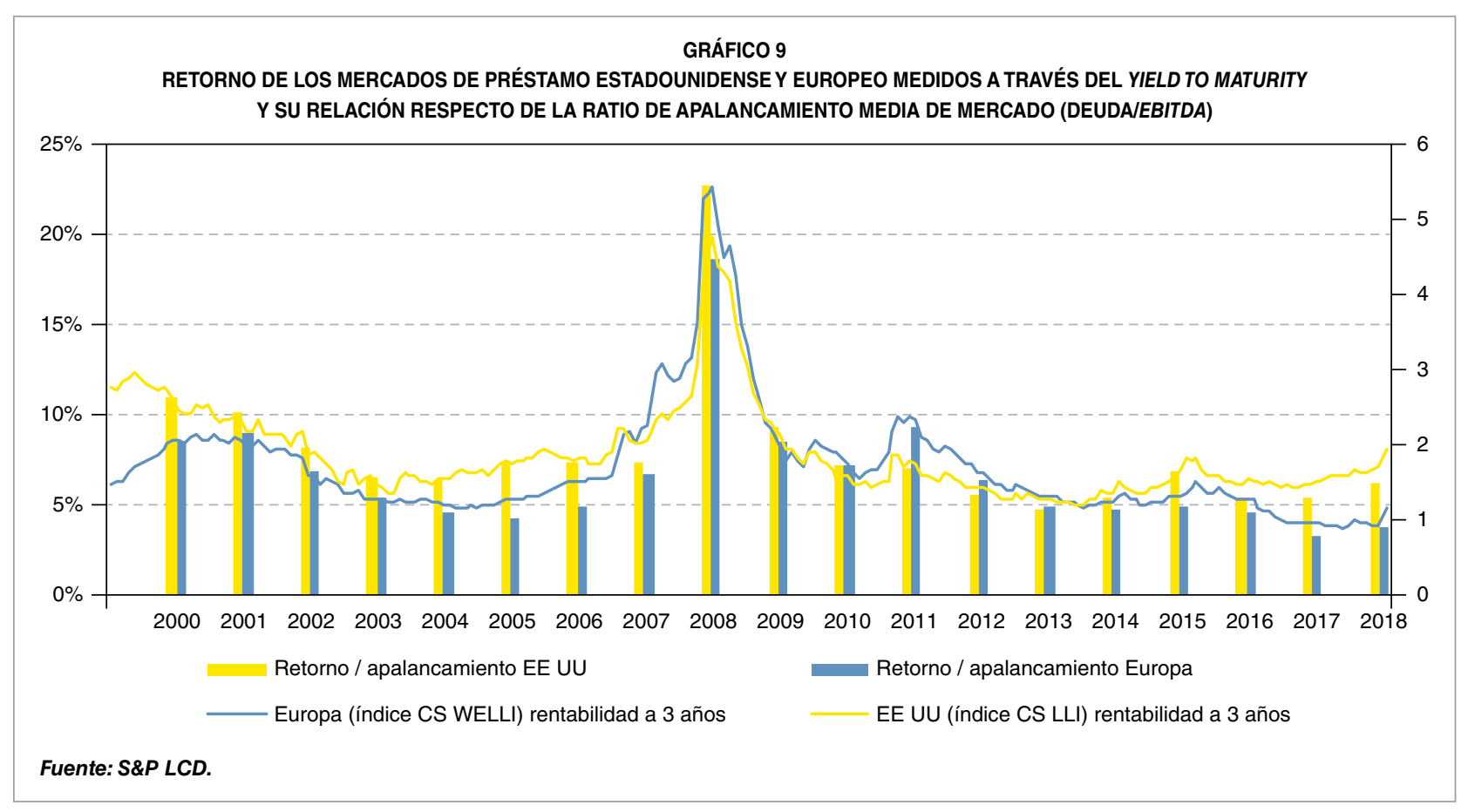

tenido como efecto colateral un deterioro de las condiciones en que se presta dinero en este mercado. La experiencia del mercado estadounidense durante la crisis demuestra que este es un mercado susceptible de sufrir rápidas correcciones, pero también súbitas recuperaciones. Cabe esperar que la próxima corrección no disfrute de tasas de recuperación tan elevadas como las históricas, si bien la dimensión de estas empresas, los colchones de capital y el carácter senior de esta deuda son factores susceptibles de proteger a los inversores de largo plazo en este mercado.

\section{Estrategias de inversión en el mercado de deuda privada}

El mercado de deuda privada ofrece al inversor la posibilidad de optar entre niveles de riesgo y retorno diferenciados, definidos por el tipo de activo que financian o por la situación de la compañía en que invierten.

\subsection{Tipología de activos del mercado de deuda privada}

Los préstamos suelen diferenciarse por su diferente nivel de prelación de crédito en el rango de acreedores y por las posibles garantías de las que puedan disfrutar.

En primer lugar, se encuentra la deuda senior o de primer rango. Estos son los primeros acreedores de la empresa, los más protegidos, pues en caso de impago son los que primero recuperan su dinero. Suelen ser siempre préstamos a tipo variable y financiar la expansión de la empresa, vía adquisición o inversión. También pueden financiar el capital circulante, si bien a veces eso se hace mediante una línea de crédito bancaria revolving y tiende a ser supersenior, es decir, incluso anterior en prelación a la deuda definida como senior.

En segundo lugar, se sitúa la deuda de segundo rango o mezzanine. La diferencia entre una y otra reside en que a veces la deuda $D$ 
mezzanine no dispone de garantías, es unsecured, siendo esta práctica más usual en Estados Unidos que en Europa. Su vencimiento es más largo que el de la deuda senior y su retorno suele ser varios puntos porcentuales superior al de la deuda senior, llegando al 10$12 \%$ como resultado de la combinación de un cupón fijo y un componente pay in kind o PIK, que consiste en que el retorno se capitaliza al vencimiento como si fuera un instrumento financiero con cupón cero. En algunos casos también puede llevar asociado un componente de retorno vía warrants (opciones sobre acciones del capital de la compañía).

A veces la empresa dispone de un único tipo de deuda denominada de tramo único o unitranche, toda ella senior sobre el capital ordinario o acciones. Esta deuda combina en un único préstamo elementos estructurales de la deuda senior y mezzanine. Viene siendo práctica usual en algunos mercados que esta posición de tramo único se divida en dos, dando lugar a lo que se llama una posición bifurcada, en la cual hay deuda senior por un importe equivalente de hasta 1,5 veces ebitda y el resto queda subordinado a ese tramo bifurcado senior. Este tramo senior suele ser vendido a bancos.

Por último, hay ocasiones en que la estructura de capital diseñada para una operación de adquisición tiene deuda a nivel de la matriz (holdco o holding company) o de una sociedad interpuesta o vehículo instrumental de la misma. Estas estructuras pueden estar aún $\triangleright$

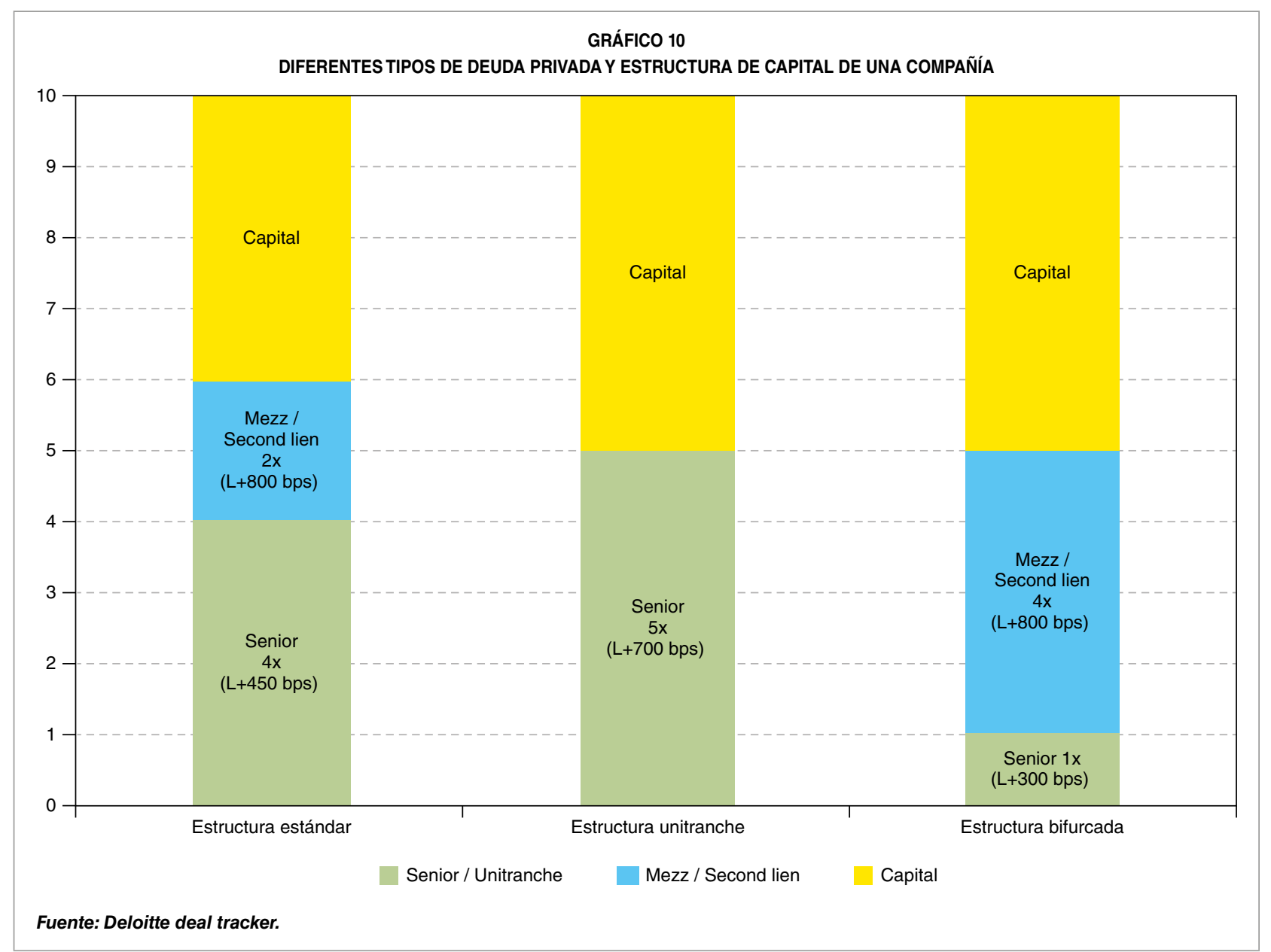


Rodrigo Echenique Sanjurjo y José María Fernández Rodríguez

más apalancadas y usar préstamos con un componente PIK cuyo retorno se acerca al del capital ordinario.

\subsection{Estrategias de inversión en el mercado de deuda privada}

Las estrategias de inversión las vamos a definir en atención a los diferentes tipos de fondos de inversión que las ejecutan y que se pueden dividir en dos grandes categorías: estrategias de preservación de capital y estrategias de apreciación de capital.

\subsubsection{Estrategias de preservación de capital}

- Direct lending o préstamos directos: los fondos que siguen esta estrategia invierten mayoritariamente en deuda senior o de tramo único. Dado que la deuda es a tipo flotante y tiene baja duración, normalmente estos préstamos cotizan en torno a la par y, por ello, el retorno financiero de estos fondos no viene dado por plusvalías de principal, sino por el cumplimiento de los términos contractuales del préstamo (cobro de intereses y comisión de estructuración esencialmente). Por todo lo anterior, la clave de esta estrategia de inversión reside en la capacidad para seleccionar buenas compañías que no impagarán sus deudas.

En Estados Unidos, buena parte de los gestores que invierten en este tipo de deuda apalancan sus fondos, es decir, toman capital a préstamo para amplificar su capacidad inversora y maximizar retornos. Ello supone un mayor riesgo potencial para el inversor en los fondos, si bien los resultados históricos de los gestores de estos fondos evidencian que el hecho de invertir en deuda senior protege al inversor de forma que los resultados de la inversión son muy atractivos sin un riesgo diferencialmente superior en la práctica, aun a pesar del apalancamiento a nivel del fondo. Así queda evidenciado en los datos presentados en la Tabla 4.

El retorno objetivo de esta estrategia depende de si se invierte solo en deuda senior o si se invierte en préstamos de tramo único y de si el fondo es apalancado, pudiendo los retornos objetivo variar entre $5 \%$ y $6 \%$ y $10 \%$ y $12 \%$.

Aun cuando por direct lending se suele hacer referencia a financiación corporativa contra los flujos de caja de la compañía y con la protección del capital ordinario de la empresa (lo que recibe la denominación inglesa de cash flow lending), hay otros tipos de préstamos directos que tienen por garantía algún colateral específico, como un activo en particular (activos financieros, cuentas a cobrar, inventario, etcétera), en cuyo caso se hace referencia a asset backed lending. En ocasiones, estas estrategias de inversión se centran en un sector o actividad específica, como en el sector de salud o el de aviación.

- Mezzanine o deuda junior. Los fondos que invierten en este tipo de deuda en principio adolecen de un mayor riesgo por su posición subordinada, su mayor sensibilidad a tipos de interés (por tener cupón fijo) y por su menor relevancia en caso de una reestructuración (dado que suele representar un $\triangleright$ 
menor porcentaje del total de la masa acreedora). Por otra parte, genera un retorno financiero notablemente superior. El retorno objetivo de esta estrategia, sin apalancamiento a nivel fondo, oscila entre el $10 \%$ y el $12 \%$.

\subsubsection{Estrategias de apreciación de capital}

Se trata de estrategias que añaden al retorno por intereses un potencial rendimiento vía revalorización del préstamo que suele cotizar, al origen de la inversión, a descuento respecto de su par o valor nominal.

- Deuda distressed: se trata de fondos que invierten en deuda impagada o en deuda que podría impagar a futuro. Dentro de este tipo de estrategia hay varias subestrategias:

1. Distressed for control: los inversores invierten en la deuda de compañías sumidas en procesos de insolvencia a precios con fuertes descuentos sobre su valor nominal al objeto de posicionarse como acreedores senior mayoritarios y con la intención de hacerse con el control del capital mediante la ejecución de debt-for equity swaps cuando se produce la reestructuración de la deuda y la compañía sale del proceso de insolvencia. Se trata de inversiones de largo plazo (2-4 años). El retorno objetivo de esta estrategia oscila entre el $17 \%$ y el $22 \%$.

2. Stressed trading: invierten en deuda que cotiza con un amplio descuento sobre el par fruto de dificultades temporales en la empresa, carencia de liquidez, riesgo idiosincrático o volatilidad en mercado. Suele tratarse de inversiones en empresas de mayor dimensión, pues sus préstamos también han de ser grandes para poder tener liquidez y mercado secundario. Son inversiones de corto plazo (hasta 18 meses). El retorno objetivo de esta estrategia oscila entre el $10 \%$ y el $15 \%$.

3. Financiación de rescate o debtor in possesion: invierten en negocios que están en bancarrota o procesos de restructuración, posicionándose de forma supersenior al resto de capital. El objetivo último no es controlar el capital de la compañía con problemas, sino maximizar la rentabilidad de la deuda con altos diferenciales, protegiéndose del riesgo de impago con posicionamientos muy senior en la estructura de capital. El retorno objetivo de esta estrategia oscila entre el $13 \%$ y el $18 \%$.

Los gestores de este tipo de fondos no suelen exclusivamente centrarse en préstamos a empresas, sino que también suelen invertir en préstamos sobre otros activos o sectores, bien sea inmobiliario o incluso préstamos al consumo, pero siempre caracterizados por atravesar algún tipo de situación estresada o de impago.

- Deuda oportunista (special situations): este tipo de deuda puede tomar diferentes formas y originarse por diferentes motivos, como spin-offs, fusiones, procesos de insolvencia o stress/distress idiosincrático, ineficiencias en las estructuras de capital, activismo o simplemente complejidad que el mercado no es capaz de entender. Puede ser deuda distressed o performing, y los préstamos pueden ser líquidos o ilíquidos. El retorno objetivo de esta estrategia oscila entre el $12 \%$ y el $20 \%$. 
A fin de caracterizar el retorno financiero generado por estas estrategias de inversión y su riesgo, la Tabla 4 presenta los retornos generados por distintos gestores durante el periodo 1986-2015, excepto para direct lending, donde el periodo abarca desde 2004 hasta 2015, con datos de la base de datos de Preqin, que engloba un conjunto de 997 fondos con un total de capital comprometido de, aproximadamente, 800.000 millones de dólares.

TABLA 4

RETORNOS OFRECIDOS POR LAS DIFERENTES ESTRATEGIAS DE INVERSIÓN EN DEUDA PRIVADA

\begin{tabular}{|l|r|r|c|}
\hline & $\begin{array}{c}\text { Retorno } \\
\text { anual }\end{array}$ & $\begin{array}{c}\text { Desviación } \\
\text { típica }\end{array}$ & $\begin{array}{c}\text { Ratio de } \\
\text { retorno/riesgo }\end{array}$ \\
\hline Direct lending & $8,58 \%$ & $2,38 \%$ & 3,61 \\
Distressed & $14,68 \%$ & $7,31 \%$ & 2,01 \\
Mezzanine & $10,73 \%$ & $4,18 \%$ & 2,57 \\
Special situations & $13,64 \%$ & $10,72 \%$ & 1,27 \\
\hline Fuente: Preqin y Altamar Credit. \\
\hline
\end{tabular}

Los resultados de este estudio evidencian los atractivos retornos financieros generados por las estrategias de inversión en deuda privada, en particular por los fondos de préstamos directos y deuda mezzanine. Un análisis más pormenorizado de la distribución de retornos por cuartiles pone de manifiesto que los tres primeros cuartiles de la citada distribución son no solo positivos, sino también superiores al $7 \%$.

El mercado de deuda privada ofrece oportunidades de inversión diferenciables por sus retornos y niveles de riesgo, y los datos presentados permiten concluir que estas estrategias han sido históricamente muy rentables. Ello no obstante, debe tenerse en cuenta que las bases de datos de este tipo de mercado suelen tener sesgos de supervivencia en virtud de que los buenos gestores tienden a estar representados, pero los malos gestores optan por no reportar datos o no son capaces de levantar más de un fondo. Dicho esto, lo que resulta evidente del estudio presentado es que hay un número no pequeño de gestores que es capaz de generar resultados muy atractivos y que hay una amplia dispersión en cuanto a los retornos obtenidos, por lo que la capacidad para seleccionar los gestores estrella es esencial al invertir en este mercado.

\section{Conclusiones}

Los mercados de préstamos apalancados disfrutan de un creciente dinamismo y, desde sus orígenes en Estados Unidos, están consolidándose en Europa y en otras geografías como una alternativa de inversión muy atractiva desde el punto de vista de rentabilidad ajustada a riesgo.

Como se ha explicado en este artículo, el deterioro de algunos de los términos y características definitorias del mercado de $\triangle$

TABLA 5

RETORNOS MEDIOS POR CUARTILES GENERADOS POR LAS DIFERENTES ESTRATEGIAS DE INVERSIÓN EN DEUDA PRIVADA A LO LARGO DEL PERIODO 1986-2015

\begin{tabular}{|c|c|c|c|c|c|}
\hline & \multirow{2}{*}{ Conjunto } & \multicolumn{4}{|c|}{ Cuartiles } \\
\hline & & 4 & 3 & 2 & 1 \\
\hline Direct lending & $9,11 \%$ & $3,93 \%$ & $7,78 \%$ & $10,14 \%$ & $14,46 \%$ \\
\hline Distressed & $13,18 \%$ & $2,51 \%$ & $9,81 \%$ & $14,24 \%$ & $26,24 \%$ \\
\hline Mezzanine & $10,49 \%$ & $2,11 \%$ & $8,77 \%$ & $11,75 \%$ & $19,23 \%$ \\
\hline Special situations & $11,56 \%$ & $-5,34 \%$ & $8,79 \%$ & $14,41 \%$ & $29,08 \%$ \\
\hline
\end{tabular}


préstamos sindicados puede llevar a pensar que, en una futura corrección, este activo sufrirá más que en pasadas crisis. Sin embargo, no ha de olvidarse que se trata de deuda senior de empresas solventes y que, aun cuando el riesgo de volatilidad es patente, tanto en la crisis de 2008 como en el más reciente episodio de volatilidad de finales de 2018 , la recuperación del mercado fue y ha sido rápida. El año 2018 fue un ejercicio difícil para los inversores en activos financieros, con pérdidas generalizadas en casi todos los mercados, con la excepción de un limitado número de activos que terminaron el año en positivo, entre los que estaba el mercado de préstamos sindicados.

El mercado de deuda privada tiene una naturaleza ilíquida y menos volátil y sus términos contractuales no se han deteriorado en la misma medida que los del mercado de préstamos sindicados. Además, algunas de sus estrategias, como las oportunistas o distress, se nutren de las oportunidades generadas en episodios de crisis sectorial o general en el mercado, por lo que pueden ser consideradas, desde este prisma, como anticíclicas. La experiencia de la crisis del 2008 evidencia que hubo gestores de fondos de deuda privada en EE UU capaces de sortear la crisis con resultados comparativamente mucho mejores que los de otros activos de inversión.

Al margen de los recientes desarrollos y circunstancias coyunturales de este mercado, los préstamos apalancados ofrecen a los inversores un activo de inversión que se ha comportado bien históricamente en escenarios de subidas de tipos de interés e inflación y que aportan un comportamiento poco correlacionado con otros activos.

Es razonable pensar que los crecientes niveles de apalancamiento y deuda global pueden ser precursores de algún tipo de corrección que podría afectar a este mercado. Sin embargo, la historia nos demuestra que esta clase de activo es capaz de ofrecer buenos rendimientos bajo distintos escenarios de mercado. A tal fin, dada la alta dispersión de retornos entre fondos y añadas, es crítico ser capaz de entender sus diferentes estrategias y de seleccionar, de entre sus gestores, a aquellos más capacitados para ejecutar con éxito la inversión en este mercado en diferentes escenarios económicos. 